\title{
An exploration of the clinical learning experience of nursing students in nine European countries
}

\author{
Tony Warne ${ }^{\mathrm{a}}$, Unn-Britt Johansson ${ }^{\mathrm{b}}$, Evridiki Papastavrou ${ }^{\mathrm{c}}$, Erna Tichelaar ${ }^{\mathrm{d}}$, Marco Tomietto ${ }^{\mathrm{e}}$, \\ Koen Van den Bossche ${ }^{\mathrm{f}}$, Maria Flores Vizcaya Moreno ${ }^{\mathrm{g}}$, Mikko Saarikoski ${ }^{\mathrm{h}, *}$ \\ a University of Salford, England, United Kingdom \\ b Sophia Hemmet University College, Sweden \\ c Cyprus University of Technology, Cyprus \\ d Windesheim University of Professional Education, The Netherlands \\ e University of Udine, Italy \\ ${ }^{\mathrm{f}}$ Catholic University of Applied Sciences of Kempen, Belgium \\ g University of Alicante, Spain \\ ${ }^{\mathrm{h}}$ University of Turku, Finland
}

\section{A R T I C L E I N F O}

\section{Article history:}

Accepted 4 March 2010

Available online $\mathrm{xxxx}$

\section{Keywords:}

Nurse education

Clinical placements

Mentorship

Professional development

\begin{abstract}
S U M M A R Y
The overall aim of the study was to develop a composite and comparative view of what factors enhance the learning experiences of student nurses whilst they are in clinical practice. The study involved students undertaking general nurse training programmes in nine Western European countries. The study focused on: (1) student nurse experiences of clinical learning environments, (2) the supervision provided by qualified nurses in clinical placements, and (3) the level of interaction between student and nurse teachers. The study utilised a validated theoretical model: the Clinical Learning Environment, Supervision and Nurse Teacher $($ CLES + T) evaluation scale. The evaluation scale has a number of sub-dimensions: Pedagogical atmosphere on the ward; Supervisory Relationships; the Leadership Style of Ward Managers; Premises of Nursing; and the Role of the Nurse Teacher. Data $(N=1903)$ was collected from Cyprus, Belgium, England, Finland, Ireland, Italy, Netherlands, Spain and Sweden using web-based questionnaire 2007-2008. The findings revealed that respondents were generally satisfied with their clinical placements. There was clear support for the mentorship approach; $57 \%$ of respondents had a successful mentorship experience although some $18 \%$ of respondents experienced unsuccessful supervision. The most satisfied students studied at a university college, and had at least a seven week clinical placement supported by individualised mentorship relationships. Learning to become a nurse is a multidimensional process that requires both significant time being spent working with patients and a supportive supervisory relationship.
\end{abstract}

(ㄷ) 2010 Elsevier Ltd. All rights reserved.

\section{Introduction}

Leaning in clinical practice provides up to half of the educational experience for students undertaking pre-registration nurse education programmes. Within practice focused professions such as nursing, the importance of this type experiential learning is considerable. The two main perspectives presented in the paper are: (1) students' experiences of their learning in clinical practice and (2) an exploration of different educational systems for pre-registration nurse training programmes in Western Europe, and in particular the clinical training placement aspect. The students' experience of their clinical placements was captured using a quantitative survey. Descriptions of the features of the various educational systems are largely drawn from a

\footnotetext{
* Corresponding author. Leppätie 13, 20720 Turku, Finland.

E-mail address: mikko.saarikoski@turkuamk.fi (M. Saarikoski).
}

review of the literature, relevant administrative documents and information given by the co-researchers in the study.

\section{Background}

The study's theoretical background reflects a range of factors that contribute to students learning in the clinical placements. The development of these factors has been discussed elsewhere (Saarikoski et al., 2008, 2009). The Clinical Learning Environment, Supervision and Nurse Teacher (CLES $+\mathrm{T}$ ) evaluation scale provides the operational framework for the study. The CLES + T scale is based on the content analysis of the results arising from a number of empirical studies $(n=87)$, audit instruments $(n=6)$ and systematic literature reviews $(n=5)$ published between 1980 and 2006 (Fig. 1).

For clarification, the pedagogical atmosphere relates to the psychosocial climate of the ward. From the viewpoint of students, the most important feature of a good learning environment is their sense of 


\begin{abstract}
CATEGORISATION OF THE THE MAIN THEMES DRAWN SUB-DIMENSIONS OF THE AREAS OF THE INCLUDED FROM THE EMPIRICAL STUDIES CLES+T SCALE: EMPIRICAL STUDIES: $\quad$ AND AUDIT INSTRUMENTS:
\end{abstract}

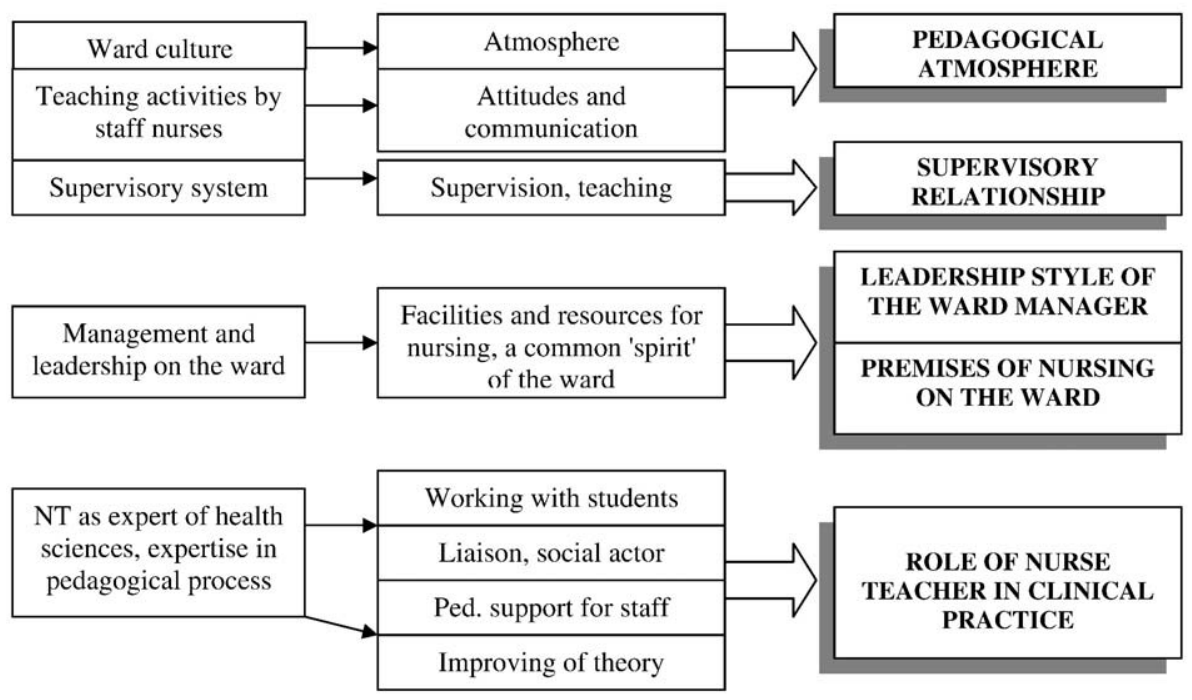

Fig. 1. Theoretical framework of the CLES+T scale.

ontological security. This is achieved in an environment, in which the atmosphere is fair and where students learn to solve problems in a culture that tolerates faults and mistakes as part of the learning process (Neville and French, 1991; Dunn and Hansford, 1997; Warne and McAndrew, 2008). In such ontologically secure working environments the students can also influence and improve the professional development of qualified nurses as new learning opportunities are developed (Wilson-Barnett et al., 1995; Saarikoski, 2002).

There is considerable evidence that a one-to-one relationship is of prime importance to the students learning and professional development in clinical practice (Campbell et al., 1994; Crawford et al., 2000; Allan et al., 2008). Confidential supervision sessions are considered important, because they enable the student to talk about their own experiences and feelings (Shatkin, 1995; Saarikoski, 2003). More traditional models for student supervision were often predicated upon group supervisory approaches. Contemporary models emphasise individualised supervisory approaches. The mentoring role of staff nurses has become increasingly central to these clinical supervision processes (Lewin, 2007).

It is often the ward manager that is most responsible for promoting a particular approach to the supervision of students learning. Likewise how the ward culture is experienced (positively or negatively) will reflect on the leadership style of the ward manager. A positive team spirit and a less hierarchical leadership style will be present within all the basic functions of the ward: the nursing care, levels of staff motivation, supervision of students and so on (Wilson-Barnett et al., 1995; Saarikoski and Leino-Kilpi, 1999). Connections between the quality of nursing care and a good learning environment have long been established (Smith, 1987, 1991). Emotional reactions in patient relationships are also important aspects of the learning experience. As the student begins to develop a sense of their professional self the relationship between this and their understanding of their personal self reflects the relationships they can develop with their patients (Saarikoski, 2003; Suikkala, 2008; Warne and McAndrew, 2008).

Nurse teachers (NT) are normally employed by a higher educational institution (HEI). They facilitate theoretical and clinical learning. As such they make a significant contribution to educational process within practice settings, including coordinating student assessments and learning. Additionally, the NT contributes to the development of clinical practice and provides support and guidance to mentors and other's who contribute to the student's overall learning experience in practice. Students benefit through meeting their learning outcomes and the development of appropriate competencies (ENB/ English National Board, 2001; Gillespie, 2002; Gardner et al., 2004).

Many dimensions of the NT's role have changed over time as educational systems moved from hospital-based or vocational school models to HEI. During the 1980s NTs were seen primarily as a clinically skilled practitioner (Nehring, 1990; Clifford, 1993) working mainly with the students' teacher and supervisor. Later studies (Cahill, 1997; Corlett et al., 2003) highlighted the importance of the NT's in the integration of theory and practice. As the supervisory role of clinical staff has grown, the role of NT has shifted to a more indirect role often acting as a liaison person between the HEI and health care provider (Newton and Smith, 1998; Ramage, 2004; Barrett, 2007).

However, in what at first glance would appear to be similar nurse education programmes across Europe, there is no universal prescription for such learning. Indeed the reverse is true. Pre-registration nurse education in Europe is characterised by different structures, standards and approaches to the relationship between theoretical and practice based learning (Salminen et al., 2009; Suhonen et al., 2009). The European Commission (2007) has, through the Bologna Treaty Process, promoted greater harmonisation of educational systems in the European area (EQF/ European Qualification Framework, 2008). Such harmonisation seeks to increase the employment and educational mobility of nursing staff and students.

\section{The study}

Aims

The overall aim of the study was to provide a composite and comparative view of what factors enhance the learning experiences of student nurses whilst they are in clinical practice.

In particular the study looked at:

(1) how nursing students experience their clinical learning environment,

(2) the supervision provided by qualified nurses of clinical placements,

(3) the level of intervention with their nurse teacher. 
Design

The context for the study reflected the approaches taken to preregistration nurse education in Western Europe. Across Europe, national nurse education systems have developed differently. There is one feature, however, common to all these developments. That is whether the system has its origins in the hospital school system or not. Where this is the case it is also important to consider the period of time taken for the transition to be achieved. The term hospital school in this paper reflects a nursing school which was part of a health care organisation, albeit often administered by a Governmental department (Järvinen, 1993; Meerabeau, 2001). For example, in Finland, the hospital school system ended in the 1960s (Järvinen, 1993). Likewise, in Cyprus the hospital school system ended in the 2000s with the first cohorts of nursing students entering a HEI in 2007. Tertiary level (degree) nurse education is most often provided in university colleges or higher professional colleges (also known as polytechnics) and these educational organisations form the HEI system in Europe (Spitzer and Perrenoud, 2006b). In this study the term polytechnic is used to describe these types of higher professional colleges. Generally, polytechnics do not tend to have traditions of being research led. The 17 nursing schools participating in the study provided a cross representation of the main approaches to pre-registration nurse education systems currently in use (Table 1). Seven nursing schools (from Belgium, Finland and Netherlands) made up a group of representing a polytechnic model and ten nursing schools represented university colleges.

Not all the differences between the participating countries were analysed due to some of the single country sub-samples generating limited data which would not permit detailed statistical analysis. The paper utilises aspects of the various education systems or draws upon the study's background variables to present the main findings.

Sample

The purposive sample $(N=1903)$ has the following attributes:

(1) All 17 schools are traditional Western European nursing schools, which have offered pre-registration nurse education and training programmes for many decades.

(2) Geographically they represent Northern Europe (5 schools), Middle Europe (6 schools) and Southern Europe (6 schools).
(3) Seven of the schools represent polytechnics (810 respondents), ten schools (1093 respondents) represent university colleges.

The participants of the study were pre-registration students (studying on General Nursing Programmes), who had their clinical placements in hospital environment. Schools from the former Eastern European countries were not included in the sample due to the many differences in nursing culture, education system and the organisation of training that would have made effective comparison difficult (Kalnins et al., 2001; Richards, 2005).

\section{Research instrument}

The research instrument used in the study is the Clinical learning environment, supervision and nurse teacher (CLES+T) evaluation scale. It is a validated research instrument, which can be used as a part of the total quality assessment of nurse education. The CLES+T scale has been validated within a Finnish study $(N=549)$ during 2007 . The psychometric properties of the scale and full content of the items have reported elsewhere (Saarikoski et al., 2008). The evaluation scale consists of 34 statements which form 5 sub-dimensions: (1) Pedagogical atmosphere on the ward - 9 items; (2) Supervisory Relationships - 8 items; (3) the Leadership Style of Ward Managers 4 items; (4) Premises of Nursing - 4 items; and (5) the Role of the Nurse Teacher -9 items. In the original instrument validation study the Cronbach's alpha values of the sub-dimensions of the scale ranged from high (0.96) to marginal (0.77). In the current European sample the reliability coefficients of the sub-dimension varied between 0.96 and 0.83 .

The questionnaire was translated into the various languages of the study participants. This process was led by the contact person in each country who translated the instrument from English to his or her own language. The items were translated using a specific three steps procedure to provide semantic equivalence (Behling and Law, 2000). The back translation was assessed by the instrument's author to confirm content validity.

There was also a sub-dimension measuring students' total satisfaction. The items were: The ward can be regarded as a good learning environment; Overall I am satisfied with the supervision I received and $I$ am satisfied with the clinical placement that has just ended. A five-step continuum scale on all statements of the CLES+T was used: (1) fully disagree; (2) disagree to some extent; (3) neither

Table 1

Basic features of the organisation of general nurse education and clinical practice within the 17 schools making up the study sample and sample sizes by the areas ( $N=1903$ ).

\begin{tabular}{|c|c|c|c|}
\hline Schools from & Responsible operative organisation of education & Duration of the total course & \%-ratio of clinical practice \\
\hline \multicolumn{4}{|l|}{ Northern Europe: (5 schools) } \\
\hline $\begin{array}{l}\text { Finland ( } 4 \text { schools) } \\
\quad n=521\end{array}$ & $\begin{array}{l}\text { Unit of polytechnic since } 1990 \text {, vocational college since } \\
1960 \text { s, earlier hospital school }\end{array}$ & $31 / 2$ years & $36 \%$ \\
\hline $\begin{array}{l}\text { Sweden ( } 1 \text { school) } \\
\quad n=134\end{array}$ & $\begin{array}{l}\text { University college since 1993, upper secondary school } \\
\text { since } 1960 \text { s, earlier hospital school }\end{array}$ & 3 years & $42 \%$ \\
\hline \multicolumn{4}{|l|}{ Middle Europe: (6 schools) } \\
\hline $\begin{array}{l}\text { Belgium (2 schools in two separate campuses) } \\
\quad n=176\end{array}$ & $\begin{array}{l}\text { Higher professional college since } 1970 \text {, vocational school } \\
\text { since } 1920 \text { s (has never been a part of hospital or health } \\
\text { care system) }\end{array}$ & 3 years & $50 \%$ \\
\hline $\begin{array}{l}\text { England (2 schools) } \\
\quad n=241\end{array}$ & $\begin{array}{l}\text { University college since } 1980 \text { s, former technical college } \\
\text { since } 1960 \text { 's, earlier hospital school }\end{array}$ & 3 years & $50 \%$ \\
\hline $\begin{array}{l}\text { Ireland ( } 1 \text { school) } \\
\quad n=118\end{array}$ & University college since 1994, earlier hospital school & 4 years & $50 \%$ \\
\hline $\begin{array}{l}\text { The Netherlands ( } 1 \text { school) } \\
n=113\end{array}$ & Unit of polytechnic since 1992, earlier hospital school & 4 years & $40 \%$ \\
\hline \multicolumn{4}{|l|}{ Southern Europe: (6 schools) } \\
\hline $\begin{array}{l}\text { Cyprus ( } 1 \text { school) } \\
n=127\end{array}$ & University college since 2007, earlier hospital school & 4 years & $50 \%$ \\
\hline Italy (3 schools) $(n=332)$ & University college since 1996 , earlier hospital school & 3 years & $33-55 \%$ (varies by the schools) \\
\hline $\begin{array}{l}\text { Spain (2 schools) } \\
\quad n=141\end{array}$ & University college since 1977, earlier hospital school & 4 years & $50 \%$ \\
\hline
\end{tabular}


Table 2

Respondents of the sample by education models.

\begin{tabular}{|c|c|c|c|c|c|c|c|c|}
\hline \multirow[t]{3}{*}{ Education model } & \multicolumn{6}{|c|}{ Respondents } & \multicolumn{2}{|c|}{ Male students } \\
\hline & \multirow[t]{2}{*}{$n$} & \multirow{2}{*}{$\begin{array}{l}\% \text { of the } \\
\text { sample }\end{array}$} & \multirow{2}{*}{$\begin{array}{l}\text { Age } \\
\text { (mean) }\end{array}$} & \multicolumn{3}{|l|}{ Classified age: } & \multirow[t]{2}{*}{$n$} & \multirow[t]{2}{*}{ Ratio } \\
\hline & & & & under 25 years & $25-35$ years & 36 years or more & & \\
\hline Unit of polytechnic & 810 & 43 & 23.4 & 637 (78\%) & $128(16 \%)$ & $45(6 \%)$ & 62 & $8 \%$ \\
\hline University college & 1093 & 57 & 25.5 & $689(63 \%)$ & $277(25 \%)$ & $127(12 \%)$ & 150 & $14 \%$ \\
\hline Total & 1903 & 100 & 24.6 & $1326(70 \%)$ & $405(21 \%)$ & $172(9 \%)$ & 212 & $11 \%$ \\
\hline
\end{tabular}

agree nor disagree: (4) agree to some extent and (5) fully agree. The alpha value of the Total satisfaction sub-instrument was 0.79 .

\section{Ethical considerations}

After administrative and ethical research approval was obtained in each country, the contact delegate from each school e-mailed the electronic questionnaire's web-link to the students as they reached the end of their clinical placement. This e-mail message acted as an information letter to participants and contained enough detail to allow students to make an informed decision to consent over whether to participate in the study or not. During the data collection phase, the respondents' right to privacy and anonymity was fully protected. The respondents made their response by e-mail; the software employed did not identify individual respondents as the design of the study did not require the use of identifiable questionnaires in data capture.

\section{Data analysis}

Data was first analysed using descriptive statistics (frequency, mean and standard deviation). The comparisons between the groups were considered using cross-tabulation or ANOVA. The reliability of each sub-dimension was analysed using Cronbach's alpha coefficient. The construct validity of the CLES+T scale was assessed using a principal components analysis. The statistical software used was SPSS 15.0.

\section{Results}

\section{Participants and clinical placements}

The mean age of the respondents was 24.6 years. There were more mature students in the university colleges than in polytechnics where the mean age was approximately two years lower (Table 2). The gender ratio between the groups was also notable; in the university colleges the male student ratio was approximately double that found in the polytechnics. In Cyprus and in Italy the male student ratios were over $21 \%$ compared to the whole sample ratio just $11 \%$.

The mean value of the clinical placement duration was 6.4 weeks. However, there was wide variation between the countries especially in the case of placements of 7 weeks or longer; $31 \%$ of respondents reported placements of 7 weeks or more but in five countries this percentage was much higher; in Netherlands 75\%, Sweden 64\%, England 50\%, Cyprus $46 \%$ and in Italy $38 \%$. Lower number of students with longer (7 weeks or more) placements were reported in Ireland (6\%) and in Spain (9\%). The longer placements were more typical in university colleges (70\%) with only $30 \%$ of polytechnics reporting these longer placements. This difference is statistically highly significant as the $p$-value in Pearson Chi-Square test was $<0.001$ in the cross-tabulation of the educational system and the dichotomy categorisation of placement duration (1-6 weeks or 7 weeks or longer).

\section{How students perceived their clinical placements}

The students evaluated their clinical placement experience positively. The mean values between the sub-dimensions varied between 3.34 and 3.91. The highest mean value was in the subdimension Supervisory relationships (3.91) and on the sub-dimension Pedagogical atmosphere on the ward (3.90). The sub-dimension Role of the NT achieved the lowest scores (mean 3.34). The duration of the placements was linked to the mean values; the students with longer placements ( 7 weeks or more) evaluated two crucial sub-dimensions clearly with the higher scores that students with shorter placements (Table 3).

\section{Occurrence of supervision}

The majority of supervisors were staff nurses (63\%). The rest of supervisor sample were made up of Specialist nurses (21\%) and WM or Assistant WM (16\%). The majority (73\%) of students had separate scheduled supervision sessions with their supervisor (without the NT) but $27 \%$ of students did not have scheduled supervision discussions with their supervisor at all. A higher frequency of supervision meetings was twice as likely to be the norm with the students in the university colleges compared to students in the polytechnics.

The questionnaire enquired about seven different experiences of supervision:

1. The student did not have a named supervisor

2. A personal supervisor was named, but the relationship with this person did not work

Table 3

Means of the sub-dimensions of the CLES +T scale by the groups (duration of the placement).

\begin{tabular}{|c|c|c|c|c|c|c|}
\hline \multirow[b]{2}{*}{ Sub-dimension } & \multicolumn{2}{|c|}{$\begin{array}{l}\text { Students with } 1-6 \text { week } \\
\text { p-ments }\end{array}$} & \multicolumn{2}{|c|}{$\begin{array}{l}\text { Students with } 7 \text { or more } \\
\text { weeks }\end{array}$} & \multirow[t]{2}{*}{$\begin{array}{l}\text { Alpha } \\
\text { value }\end{array}$} & \multirow[t]{2}{*}{$\begin{array}{l}p \text {-value in } \\
\text { ANOVA }\end{array}$} \\
\hline & Mean & SD & Mean & SD & & \\
\hline Pedagogical atmosphere on the ward & 3.86 & 0.93 & 4.00 & 0.90 & 0.93 & $0.002^{* *}$ \\
\hline Mentorship relationship & 3.84 & 1.09 & 4.05 & 1.01 & 0.96 & $0.000^{* * *}$ \\
\hline Leadership style of the ward manager & 3.59 & 1.00 & 3.61 & 0.94 & 0.86 & 0.621 \\
\hline Premises of nursing on the ward & 3.78 & 0.86 & 3.84 & 0.84 & 0.83 & 0.175 \\
\hline Role of nurse teacher & 3.33 & 0.96 & 3.34 & 0.95 & 0.92 & 0.949 \\
\hline
\end{tabular}

** Significant if $p<0.01$.

*** Significant if $p<0.001$. 
Table 4

The item sub-groups of the Role of nurse teacher (NT), means by the groups of history of the hospital school phase.

\begin{tabular}{|c|c|c|c|c|c|}
\hline \multirow[t]{2}{*}{ The item sub-groups ( 3 items in the every group) } & \multicolumn{2}{|c|}{$\begin{array}{l}\text { Short history }(<20 \text { years }) \text { from } \\
\text { hospital school }(n=831)\end{array}$} & \multicolumn{2}{|c|}{$\begin{array}{l}\text { Long history ( }>20 \text { years) from } \\
\text { hospital school }(n=896)\end{array}$} & \multirow[t]{2}{*}{$\begin{array}{l}p \text {-value in } \\
\text { ANOVA }\end{array}$} \\
\hline & Mean & St. Dev. & Mean & St. Dev. & \\
\hline NT enabling integration of theory and practice & 3.58 & 1.09 & 3.49 & 1.07 & 0.087 \\
\hline Co-operation between placement staff and NT & 2.97 & 1.19 & 2.77 & 1.18 & $0.001^{* * *}$ \\
\hline Relationship between student, mentor and the NT & 3.55 & 1.09 & 3.53 & 1.67 & 0.734 \\
\hline
\end{tabular}

*** Significant if $p<0.001$.

3. The named supervisor changed during the training course, even though no change had been planned

4. The supervisor varied according to shift or place of work

5. The supervisor had several students and was a group supervisor rather than an individual supervisor

6. A personal supervisor was named and the relationship worked during the placement

\section{Other}

The first three alternatives were combined into one new group: Unsuccessful supervisory experience; alternatives four and five were combined as: Group supervision; alternative six was renamed: Successful supervisory experience. When the data was reconsidered against these revised designations, 57\% assessed that they had a successful mentorship, 25\% had group supervision, 15\% had some variation of an unsuccessful supervisory experience. Unfortunately the worst case experience - a completely absent supervisor - occurred with 63 students (3\%) of all respondents.

The nurse teacher's role

In the original factor analysis of the CLES $+\mathrm{T}$ scale the subdimension Role of NT produced different outcomes from those of the current European sample when compared with the original Finnish validation sample (see Saarikoski et al., 2008). In the original validation analysis the Role of NT formed an independent factor (congruent with the theoretical prediction). However, in the current factor analysis the Role of NT was split into two different factors. A more detailed analysis of the sub-dimension of the Role of $N T$, was therefore undertaken. In the questionnaire nine items of the Role of NT were given to the respondents using three sub-titles:

(1) the NT enabling integration of theory and practice -3 items;

(2) Level of co-operation between the placement staff and NT -3 items and

(3) the relationship between student, mentor and the NT -3 items.

There were no notable differences in the mean values related to the various education systems or geographical areas but when linked to the history of hospital school system a difference was evident (Table 4). Respondents from Belgium $(n=176)$ were excluded from this analysis as the Belgian nurse education system has never been part of a hospital system.

\section{Student satisfaction}

Students were mainly satisfied with their clinical placements; $42 \%$ of respondents were satisfied or very satisfied and $44 \%$ were neither dissatisfied nor satisfied. A clear minority (14\%) was formed by dissatisfied or very dissatisfied students. The occurrence of supervisory relationships was linked to the student's level of satisfaction. In the cross-tabulation, those dissatisfied students corresponded with the group of students reporting an Unsuccessful supervisory experience (47\%), and likewise, satisfied students corresponded to the group Successful mentorship experience (75\%). The $p$-value in Pearson ChiSquare test was $<0.001$ (see Table 5 ).

Total satisfaction was also considered against a number of relevant background variables (age, gender, year of study and so on) but no correlations were revealed. However, a clear connection was found with the Duration of the placement; students who had longer clinical placements had a higher mean value (4.10) with their level of satisfaction than students who had had shorter placements (3.97); the $p$-value in ANOVA was 0.006. The level of satisfaction of the students also varied with the type of educational system; students in the university colleges were more satisfied (4.05) than students from polytechnics (3.95). The difference in means was statistically significant ( $p$-value in ANOVA 0.03).

Because 7 weeks or longer placements were more common with students in the university colleges, the interaction between the variables Duration of the placement and Education system was tested. In a two-way analysis of variance the dependent variable was Students' total satisfaction. The $p$-value of the interaction effect was 0.72 that is; the interdependence between Duration of the placement and Students' total satisfaction was not affected by the educational system. Likewise students in the polytechnics who had longer placements were more satisfied than students with short placements.

\section{Discussion}

The greatest structural differences in this study were the percentage ratio of clinical practice (within the total course) and

Table 5

Cross-tabulation of Occurrence of supervision and Students' total satisfaction (percentages and frequency's).

\begin{tabular}{|c|c|c|c|c|}
\hline \multirow[t]{2}{*}{ Occurrence of supervision: } & \multicolumn{4}{|l|}{ Total satisfaction: } \\
\hline & Unsatisfied students & Neither unsatisfied, nor satisfied stud. & Satisfied students & Total \\
\hline Unsuccessful experience of supervision & $47 \%(121)$ & $14 \%(123)$ & $4 \%(36)$ & 280 \\
\hline Group or team supervision & $28 \%(71)$ & $30 \%(249)$ & $19 \%(147)$ & 467 \\
\hline Successful mentorship & $21 \%(55)$ & $53 \%(441)$ & $75 \%(597)$ & 1093 \\
\hline Other occurrence of superv. & $4 \%(9)$ & $3 \%(23)$ & $2 \%(16)$ & 48 \\
\hline Total & $100 \%(256)$ & $100 \%(836)$ & $100 \%(796)$ & 1888 \\
\hline
\end{tabular}

Chi-Square tests $p$-value $<0.001$ (the differences between the groups statistically highly significant).

0 cell $(0 \%)$ have expected count less than 5 , the minimum expected count is 6.51 . 
the duration of the placements which varied between 1 and 42 weeks. The duration of the placement has a connection to levels of satisfaction. Students with longer placements were more satisfied. This is a result not found in previous studies. The approach adopted in this study does not easily reveal the explanatory evidence for this result but some interpretations can be made. Learning to become a nurse is a multidimensional process that requires exposure to appropriate amounts of time being spent with patients. This time and the available learning opportunities are then best supported within effective and regular supervisory discussions, with knowledgeable supervisors. During short placements students might learn a range of technical skills but may get fewer opportunities to integrate those skills with the development of their interpersonal skills in building effective and therapeutic relationships with their patients. Arguably, there are also greater opportunities within longer placements for students to more effectively learn about working more interdependently with other members if the team.

A clinical ward is a complex entity made up of many integrated subsystems. The pedagogical atmosphere was seen to be an important aspect of the clinical learning environment in this study. However, the most important single element in clinical learning experience was the supervisory relationship. This is congruent with the earlier studies carried out in Finland (Saarikoski, 2002; Saarikoski et al., 2008) during the validation phase of the CLES+T scale. According to these previous studies there was an ongoing transition process occurring that suggested a move from group supervision approach to a one-to-one supervision orientation. In the current European study only $25 \%$ of respondents had experienced a group supervision model. There was a clear trend toward an individual Mentorship model. Across the whole sample 57\% of students experienced successful Mentorship relationships. Whilst there were not many differences between educational systems, we found that the supervisory models varied widely across the countries. For example in England ( $n=214$, the data collected from 2 schools) 74\% of respondents had successful Mentorship experience, in Finland ( $n=521$, from 4 schools) the corresponding value was $69 \%$ and in Italy ( $n=332$, from 3 schools) it was $63 \%$. These three countries represent over half of the total sample. The average rate of successful Mentorship experiences in the remaining countries was $45 \%$. The majority of students who had regular (once a week of more) supervisory discussions with a supervisor were from the university colleges.

The splitting of the sub-dimension Role of NT, undertaken in the analysis of data collected from this European sample shows that the differences between countries is most evident in the clinical role. It is important to recognise that the other four sub-dimensions of the CLES + T scale supported the theoretical presumptions of the study (Saarikoski et al., 2008, 2009). More detailed comparisons by the subgroups of the items revealed that these differences could be seen particularly with the changing nature of the way in which the NT worked with the wards nursing team. An additional mediating factor however, appeared to be the amount of time that was involved in moving away from a hospital school based approach to a HEI based approach to nurse education. The changing nature of the NT's role is a visible indicator of the cultural change resulting from such transitional changes to pre-registration nurse education systems.

There are limitations to this study. The size and the cross generalisation of the sample was problematic. Despite the overall sample size (1903 respondents) being notable, only very preliminary interpretations rather than wide generalisations are possible. A more detailed analysis using - e.g. comparisons of the countries - would require larger individual country sub-samples which would help resolve this limitation in future studies of this nature. Likewise, it can also be argued that the quantitative survey method is unable to produce the kind of detailed information which would be needed in understanding more fully some of the qualitative and conceptual aspects of factors such as 'satisfaction'. For example interviews of students could provide some additional information and richer explanations of the lived experience. In the questionnaire, there were no open-ended questions, which might have provided more examples of what was understood by the level of student satisfaction.

\section{Conclusions and implications}

The duration of clinical placement appeared to influence the level of overall student satisfaction and how the quality of supervisory relationship and the pedagogical atmosphere on the ward was experienced. It is clear that a nursing student who sees the whole individual nursing process over a longer period, and with the same patient, is likely to gain a clearer understanding of the role of nurse than one who has only participated in a series of disconnected tasks during a two or three week placement. In longer patient relationships the student can learn to recognise crucial elements of the caring relationship and also become aware of her or his own emotional reactions within these relationships. The importance of the length of clinical placements will need more detailed exploration but already this study has provided some preliminary evidence that supports the importance of providing longer placements for students. Nurse educators need to consider carefully the balance of providing many short (1-2 weeks) forms of clinical experiences versus the holistic experience of nursing care that might be achieved during a longer placement.

The mentorship relationship was also seen to be an important element in the students' total satisfaction. In an individualised supervisory relationship the student experience can be more uniquely tailored to reflect the students learning needs. Such a relationship can help students in their professional development and in recognition of his or her professional and personal self. This kind of relationship requires time to develop. We argue that working with patients and effective mentorship relationships are core elements of professional development in nursing. These two factors need to be recognised more formally in the planning of clinical courses. The results of this study prompt the need for further work in this area, particularly around the different approaches to providing learning opportunities in clinical practice. However, there may also be some advantages in undertaking further comparative analysis of the link between practice based learning and the theoretical and pedagogical approaches used.

Spitzer and Perrenoud (2006a,b) have analysed the status of nursing education and its relationship to other educational reforms in 20 Western European countries. Their analysis was based upon a review of the literature and official policy documents of the educational systems in these countries. They reported a wide variation of existing structures, level of education and duration of the studies. Although the current empirical study was focused only on the clinical practice elements of pre-registration nurse training programmes, there is a high degree of congruence with the wider findings of Spitzer and Perrenoud's work. There were wide variations in how clinical placements were organised in the nine countries. This is notwithstanding the fact that these nine countries should be drawing upon a uniform approach to nurse education as set out by the many EU directives since the end of 1990s. It is likely that had the sample also included the new EU countries, the differences in the educational provision would have been even greater. Clearly the processes of harmonising nurse educational systems are still an emergent phenomenon in the EU. The differences in the structural issues study reveal that the nine countries are still at different development phases of educational reform. The influence of the organisational development and transition processes (hospital school, vocational college, polytechnic, and university college) are also revealed. The role-dimensions of the NT act as a good indicator of the stage of development of the various educational systems. Given the results of this study, there is a clear need to develop more cross European studies aimed at investigating further the best practice examples of the way in which nurse education and student learning can more effectively be facilitated in clinical practice environments. 


\section{Acknowledgement}

The study was supported by The Nurse Education Foundations (Sairaanhoitajien koulutussäätiö) fund.

\section{References}

Allan, H.T., Smith, P.A., Lorenzon, M., 2008. Leadership for learning: literature study of leadership for learning in clinical practice. Journal of Nursing Management 16 545-555.

Barrett, D., 2007. The clinical role of nurse lecturers: past, present and future. Nurse Education Today 27, 367-374.

Behling, O., Law, K.S., 2000. Translating Questionnaires and Other Research Instruments: Problems and Solutions. Saga Publications Inc., Thousand Oaks.

Cahill, H.A., 1997. What should nurse teacher be doing? A preliminary study. Journal of Advanced Nursing 26, 146-153.

Campbell, I.E., Larrivee, L., Field, P.A., Day, R.A., Reutter, L., 1994. Learning to nurse in the clinical setting. Journal of Advanced Nursing 20, 1125-1131.

Clifford, C., 1993. The clinical role of the nurse teacher in the United Kingdom. Journal of Advanced Nursing 18, 281-289.

Corlett, J., Palfreyman, J.W., Staines, H.J., Marr, H., 2003. Factors influencing theoretical knowledge and practical skill acquisition in student nurses: an empirical experiment. Nurse Education Today 23, 183-190.

Crawford, M.J., Dresen, S.E., Tschikota, S.E., 2000. From 'getting to know you' to ‘soloing': The preceptor-student relationship. NtResearch 5, 5-19.

Dunn, S.V., Hansford, B., 1997. Undergraduate nursing student' perceptions of their clinical learning environment. Journal of Advanced Nursing 25, 1299-1306.

European Commission, 2007. Education and Training [online] Available from the World Wide Web: <http://europa.eu.int/comm/education/policies/2010/et_2010_en. html $>$ (referred 22.11.2008).

EQF/ European Qualification Framework, 2008. Position paper on synergy between Directive 36, Bologna and European Qualifications Framework. Available from www: http://www.efnweb.org/version1/en/documents/EFNPositionStatementonSynergyMRPO-Bologna-EOF-EN-final102008.pdf (referred 11.06.2009)

ENB/ English National Board, 2001. Placements in Focus. Guidance for Education in Practice for Health Care Professions. ENB, Department of Health, Chiltern Press, Luton.

Gardner, G., Gardner, A., Proctor, M., 2004. Nurse practitioner education: a researchbased curriculum structure. Journal of Advanced Nursing 47, 143-152.

Gillespie, M., 2002. Student-teacher connection in clinical nursing education. Journal of Advanced Nursing 37, 566-576.

Järvinen, M., 1993. Koulutus hoivatyöhön: Terveydenhuoltoalan koulutuksen muotoutuminen ja tulevaisuudennäkymät. Research Unit for the Sociology of Education, University of Turku, Painosalama Oy, Turku.

Kalnins, I., Barkauskas, V.H., Seskevicius, A., 2001. Baccalaureate nursing education development in 2 baltic countries: outcomes 10 years after initiation. Nursing Outlook 49, 142-147.

Lewin, D., 2007. Clinical learning environments for student nurses: Key indices from two studies compared over a 25 year period. Nurse Education in Practice 7 , 407-415.
Meerabeau, E., 2001. Back to the bedpans: the debates over preregistration nursing education in England. Journal of Advanced Nursing 34, 427-435.

Nehring, V., 1990. Nursing clinical teacher effectiveness inventory: a replication study of the characteristics of "best" and "worst" clinical teachers as perceived by nursing faculty and students. Journal of Advanced Nursing 15, 934-940.

Neville, S., French, S., 1991. Clinical education: students' and clinical tutors' views. Physiotherapy 77, 351-354.

Newton, A., Smith, L.N., 1998. Practice placements supervision: the role of the personal tutor. Nurse Education Today 18, 496-504.

Richards, R., 2005. Development in Eastern Europe. Mental Health Nursing 25, 10-12. Ramage, C., 2004. Negotiating multiple roles: link teachers in clinical practice. Journal of Advanced Nursing 45, 287-296.

Salminen, L., Stolt, M., Saarikoski, M., Suikkala, A., Vaartio, H., Leino-Kilpi, H., 2009. Future challenges for nursing education - A European perspective. Nurse Education Today 30, 233-238.

Saarikoski, M., 2002. Clinical learning environment and supervision. Development and validation of the CLES evaluation scale. PhD-thesis, Annales Universitatis Turkuensis D 525, Kirjapaino Pika Oy, Turku.

Saarikoski, M., 2003. Mentor relationship as a tool of professional development of student nurses in clinical practice. The International Journal of Psychiatric Nursing Research 9, 1014-1024.

Saarikoski, M., Leino-Kilpi, H., 1999. Association between quality of ward nursing care and students' assessment of the ward as a clinical learning environment. NTresearch 4, 467-474.

Saarikoski, M., Isoaho, H., Warne, T., Leino-Kilpi, H., 2008. The Nurse Teacher in clinical practice: developing the new sub-dimension to Clinical Learning Environment and Supervision (CLES) scale. International Journal of Nursing Studies 45, 1233-1237.

Saarikoski, M., Warne, T., Kaila, P., Leino-Kilpi, H., 2009. The role of the nurse teacher in clinical practice: an empirical study of Finnish student nurse experiences. Nurse Education Today 29, 595-600.

Shatkin, L., 1995. Clinical teaching as part of psychiatric nursing education. The International Journal of Psychiatric Nursing Research 2, 134-145.

Smith, P., 1987. The relationship between quality of nursing care and the ward as a learning environment: developing a methodology. Journal of Advanced Nursing 12, 413-420.

Smith, P., 1991. The nursing process: raising the profile of emotional care in nurse training. Journal of Advanced Nursing 16, 74-81.

Suhonen, R., Saarikoski, M., Leino-Kilpi, H., 2009. Cross-cultural research: a discussion paper. International Journal of Nursing Studies 46, 593-602.

Suikkala, A., 2008. Nursing student-patient and associated factors. PhD-thesis, Annales Universitatis Turkuensis D 788, Painosalama Oy, Turku.

Spitzer, A., Perrenoud, B., 2006a. Reforms in nursing education across Western Europe: from agenda to practice. Journal of Professional Nursing 22, 150-161.

Spitzer, A., Perrenoud, B., 2006b. Reforms in nursing education across Western Europe: implementation process and current status. Journal of Professional Nursing 22, $162-171$.

Warne, T., McAndrew, S., 2008. Painting the landscape of emotionality: colouring in the emotional gaps between the theory and practice of mental health nursing. International Journal of Mental Health Nursing 17, 108-115.

Wilson-Barnett, J., Butterworth, T., White, E., Twinn, S., Davies, S., Riley, L., 1995. Clinical support and the Project 2000 nursing student: factors influencing this process. Journal of Advanced Nursing 21, 1152-1158. 